(C) Springer-Verlag 1992

\title{
La page du T.I.M.S.
}

A. Wackenheim

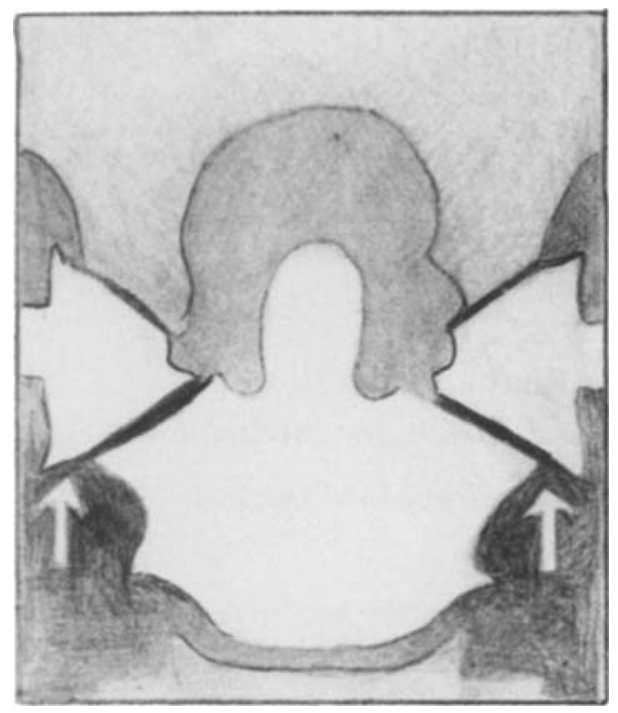

A 42

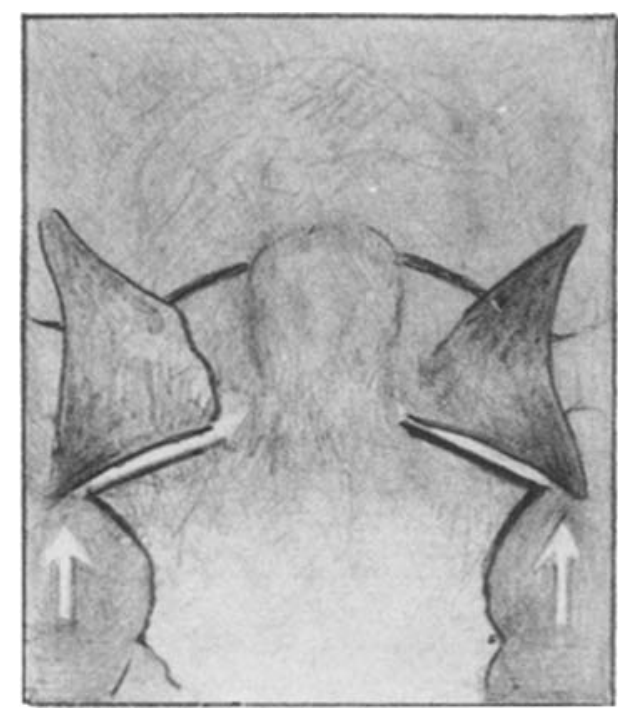

A 43

\section{A 42}

Désalignement latéral de l'atlas par rapport à l'axis dans un cas de fracture de Jefferson (scanographie)

Lateral desalignement of the atlas on the axis in a case of Jefferson fracture $(\mathrm{CT})$

Laterale Axis-Überlagerung des Atlas bei Jefferson'scher Fraktur (CT)

\section{A 43}

Désalignement latéral de l'atlas par rapport à l'axis par hypertrophie osseuse de l'atlas dans un cas de maladie de Paget (IRM)

Lateral desalignement of the atlas on the axis by hypertrophy of the atlas in Paget disease (MRI)

Laterale Axis-Überlagerung des Atlas durch Hypertrophie des Atlas bei Morbus Paget (MRI) 